\title{
COMPENSATION DISPERSION BETWEEN AND WITHIN HIERARCHICAL LEVELS*.
}

\author{
PEDRO ORTÍN-ÁNGEL. \\ Dpt. Economía de la Empresa. \\ Universidad Autónoma de Barcelona. \\ 08193 Bellaterra, Barcelona, Spain. \\ pere.ortin@uab.es \\ VICENTE SALAS-FUMÁS. \\ Dpt. de Economía y Dirección de Empresas. \\ Universidad de Zaragoza. \\ 50005 Zaragoza, Spain. \\ vsalas@unizar.es
}

\begin{abstract}
:
This paper studies the dispersion around the expected compensation of workers before and after controlling for hierarchical positions in cross-section data samples. From data for Spanish managers, we find that this dispersion decreases with education and work experience before entering the current job and increases with job tenure. This finding contrasts with previous research that finds a positive association between compensation dispersion and education and work experience. We explain the new finding through a model of learning that separates compensation dispersion between jobs and within jobs (hierarchical positions). The model takes advantage of the information revealed when workers are promoted to their current hierarchical positions and allows for more robust tests of learning theories.
\end{abstract}

JEL classification: J33, J41, D83.

Keywords: Learning process, Labor Compensation, Compensation dispersion.

\author{
CORRESPONDING AUTHOR: \\ PEDRO ORTÍN ÁNGEL. \\ DPTO. ECONOMÍA DE LA EMPRESA. \\ EDIFICIO B. \\ UNIVERSIDAD AUTÓNOMA DE BARCELONA. \\ 08193 BELLATERRA (BARCELONA). \\ SPAIN.
}

TEL. 34- 93- 5811451

FAX. 34-93- 5812555

E- mail : PERE.ORTIN @ UAB.ES

\footnotetext{
* The authors wish to thank two anonymous referees, the coeditor and the editor of the Journal for their comments and Mr. Manuel Osorio, from I.C.S.A., for making the data used in this study available to us and to any researcher for purposes of replication. Part of this paper was written while Pedro Ortín was visiting the Management Department at Texas A\&M, with the financial support of the Spanish Ministry of Education. This work has received financial support from the BEC2001- 2552-C03-01.
} 


\section{INTRODUCTION}

Traditional human capital theory (Becker, 1964, and Mincer, 1974) explains differences in the compensation of workers as a result of differences in their observed ability (e.g. level and type of formal education, experience and training). A variant of human capital theory is the learning models in which ability and competence are not observable at the time a worker enters the labour market, but can be learned by employers from what is observed from the way the job is performed (e.g., Harris and Holmstrom, 1982). Salaries can therefore change over time for two reasons. Because employees acquire new abilities, or because the information about their ability improves and they can be better matched to job positions.

Learning models are playing an increasingly greater role in the study of labor markets $^{1}$, but there is the impression (Baker et al., 1994, and Gibbons and Waldman, $1999 \mathrm{~b})$ that more empirical work is needed for better evaluation of the relevance of comprehensive human capital theories in explaining compensation and careers in organizations. This paper contributes to this field of study by providing a new prediction for and empirical evidence of the relevance of learning about hidden ability in explaining work assignments and wage formation in hierarchical organizations.

\footnotetext{
1 Some of the research in this area assumes observed and unobserved ability interact and affect managerial decisions. For example, formal education can be a signal of hidden innate ability (Spence 1976, and Salop and Salop 1976). Hidden ability increases the rate of human capital accumulation with labor experience (Gibbons and Waldman, 1999a), or it provides new capabilities from those acquired through education and training (Farber and Gibbons, 1996). Other research demonstrates the need to design short-term performance-based incentives, taking into account that high-powered incentives may distort the information content of the output about the hidden ability of the employee, introducing "career concerns" in the design of incentives (Holmstrom 1982, Gibbons and Murphy 1992, Auriol et al. 2002, and Andersson, 2002). Finally, the labor market may be distorted because employees, aware of the signaling effects of the outcome of their decision (for example, on the decision whether to promote them) can act strategically in choosing which projects to implement (Chevalier and Ellison, 1999), or in preparing earnings forecasts (Hong and Kubik, 2003). On the other hand, employers reveal information about the ability of workers when making job assignments and, since this may increase salaries with retained workers, job assignments may be strategically delayed by the employers (Waldman 1984, 1990, Bernhardt 1995, and Gibbons and Waldman 1999a).
} 
One of the earliest empirical supports for learning theory comes from the evidence that compensation dispersion is higher for employees with more work experience and more years of schooling (Mincer, 1974). Learning enables better matching of employees to jobs over time and, therefore, the observed dispersion of salaries should converge with the true dispersion of hidden ability among employees that enter the job market at the same time (Harris and Holmstrom, 1982). Our paper provides empirical evidence that appears to contradict this stylised fact, since we find that the compensation dispersion of the managers in our sample decreases with work experience and increases with job tenure. In other words, within the current job, compensation dispersion decreases with work experience in previous jobs and increases with tenure of the current one.

We interpret this result as evidence that workers enter a particular job (a hierarchical position in our case) with similar expected abilities, equal to those required to perform the job, but with different levels of precision in the estimation. In the new hierarchical position, learning continues but at a rate that is inversely related to the information available about the worker's ability at the time of being promoted. Precision in the estimated ability at the time of being assigned to a new job increases with the worker's formal education and work experience at that moment in time. The reason for this is that formal education helps improve the process of sorting workers into jobs when they enter the labour market, and greater experience implies more previous performances, which subsequently reduces the noise of the information used to infer ability.

When compensation dispersion is estimated across job positions, the variance of compensation reflects the dispersion in beliefs about the distribution of the hidden ability of workers in those jobs. Older workers will be better matched to jobs and dispersion of salaries across jobs for workers of a given age will increase with age. This is Mincer-type empirical evidence, which is also confirmed by our empirical results. Within jobs, however, observed salaries correspond to the estimated ability required for those jobs and the compensation dispersion we observe inversely reflects the precision with which such an estimation is made. If the compensation dispersion within a job 
decreases with the information available at the time of entry, there is evidence that employers learn about the hidden abilities of individual workers, which is the way learning theory is formulated in Harris and Holmstrom (1982).

Therefore, the methodology followed in the paper provides an alternative way of testing learning theory to that used in Farber and Gibbons (1996), Altonji and Pierret (2001), and Bauer and Haisken-DeNew (2001). In these papers, the hypothesis of employer learning is transformed into the hypothesis that AFQT scores ${ }^{2}$ (or other proxies of innate ability) will show higher correlation with observed salaries as work experience increases. Empirical evidence confirming this hypothesis can be interpreted in support of the learning theory as long as we assume that, at the time workers are hired, employers cannot observe other variables that are highly correlated with the AFQT scores. Our empirical tests of learning do not depend on this assumption.

Empirical evidence showing a positive association between compensation dispersion and job tenure has also been interpreted as evidence supporting learning theory (Murphy, 1986; Foster and Rosenzweig, 1993; Baker et al., 1994 and Poppo and Weigelt, 2000). But we show that compensation dispersion can increase with job tenure for reasons other than learning, suggesting that more robust explanations are needed. Our result that compensation dispersion decreases with experience before entering the current job is more difficult to explain using alternative theories.

The paper also contributes to the existing literature through a new two-equation empirical model, one for the level of compensation and another for conditional dispersion, in order to test the theoretical predictions. The methodology is based on Harvey's (1976) approach to dealing with multiplicative heteroskedasticity. Although our main interest lies in the dispersion equation, certain insights are also provided into

\footnotetext{
2 The Armed Forces Qualifying Test (AFQT) score is based on the results of the Armed Forces Vocational Aptitude Battery tests used by Farber and Gibbons (1996) which is explained in their paper, p 1022 .
} 
the return on job human specific capital and the question of whether innate and acquired abilities interact in determining the productivity of an employee at a given moment in time.

The paper is organized as follows. In section two, we summarize the empirical implications of learning models in studying the determinants of workers' compensation when information is available about workers' job positions. Section three contains a description of the database and methodology and presents the results of the estimation of the empirical model. The discussion of the evidence supporting the basic theory is included in section four. In section five, we conclude the paper with a brief summary of the main findings.

\section{THEORETICAL DISCUSSION}

Since Mincer (1974) standard human capital models have studied the conditional expected wage $\mathrm{E}\left(\operatorname{Ln} w / X_{i}\right)$ and the conditional variance $\operatorname{var}\left(\operatorname{Ln} w / X_{\mathrm{i}}\right)$ in samples of workers using information about wages, $\operatorname{Ln} w_{i}$, and other observable characteristics, $X_{i}$, of worker $i$, such as age $(A)$ and years of schooling $(S), X_{i}=\left(S_{i}, A_{i}\right)$.

When information is available, the conditional expected salary is estimated by controlling for job positions of workers ${ }^{3}$. For example, if we know the hierarchical position of the worker in the firm, we can define a set of n dummy variables, $H_{l} \ldots H_{L}$ $\ldots H_{n}$, where $H_{L}$ is a variable that takes the value of 1 if worker $i$ is placed in job position $L$ and 0 otherwise, for $L=1, \ldots, \mathrm{n}$, hierarchical levels. Then, with this information together with the age and the years of schooling of the worker, $Z_{i}=\left(S_{i}, A_{i}, H_{L}\right)$, the conditional expected wage is equal to $\mathrm{E}\left(\operatorname{Ln} w / Z_{i}\right)$.

\footnotetext{
${ }^{3}$ See for example, Leonard (1990) and Gerhart and Milkovich (1990).
} 
However, the implications for the conditional variance of compensation, $\operatorname{var}(\mathrm{Ln}$ $w / Z_{i}$ ), of including information about job positions in human capital models have yet to be empirically explored. The main purpose of this section is to extend previous learning models by investigating within-job compensation variance when the job position is represented by the hierarchical level of workers in firms. The extension builds on papers by Farber and Gibbons (1996), Altonji and Pierret (2001) and Gibbons and Waldman (1999a). We also provide predictions for compensation variance from human capital models where innate abilities are assumed to be public knowledge, which can be viewed as alternatives to the learning theory.

\subsection{Preliminary assumptions}

i) Workers' ability

Let $a_{i}$ be the innate ability of worker $i$. We consider a setting involving overlapping generations where there is a shared belief that the innate ability of workers for each generation is distributed among the population as a normal random variable $a$ with mean $\bar{a}$ and variance $\sigma_{a}^{2}$.

Workers can increase their ability over time through formal education, schooling, experience and in-job training. Let $h_{i, t}$ be the ability of worker $i$ at period $t$ of her life, which depends on innate ability, $a_{i}=h_{i, 0}$, and on the acquisition of additional ability through regular investment in human capital, $r_{t} ; h_{i, t}=f\left(a_{i}, r_{1}, \ldots, r_{t}\right)$. The investments, $r_{t}$, are public knowledge. To simplify the exposition, we assume that investment is constant for every period of time but can be different in the period of schooling, $r_{t}=c_{1}$, and in the period of work experience, $r_{t}=c_{2}$.

\section{ii) Productivity and organization of production}

Like Altonji and Piarret (2001) and Farber and Gibbons (1996), we define $y$ as the logarithm of the productivity of a worker with ability $h$, at a given moment of her life $t$ as, $y_{i, t}=h_{i, t}+v_{t}$, where $v_{t}$ is an error term with mean zero, variance $\sigma_{V}^{2}$ and 
uncorrelated with contemporaneous ability and previous errors. Production level $y$ is public knowledge.

Production takes place in multi-level organizations and workers are assigned to hierarchical levels in accordance with their estimated ability ${ }^{4}$. For the sake of simplicity, consider that firms have $\mathrm{n}$ hierarchical levels, $L=1,2,3, \ldots, \mathrm{n}$, where top management corresponds to level 1 . Let $m_{L}$ be the minimum ability required to be assigned to hierarchical level $L$, where $m_{1}>m_{2}>m_{3}>\ldots . m_{\mathrm{n}-1}>m_{\mathrm{n}}=0$. We normalize the productivity of the workers on the basis of the minimum productivity needed to be placed at the lowest hierarchical level of the firms, $e^{m_{n}}=1$.

\section{iii) Information about innate abilities}

In accordance with such learning models as Altonji and Piarret (2001) and Farber and Gibbons (1996), we assume that employers and employees know all parameters except the innate ability of a particular worker. The innate ability can be inferred, however, from informative signals provided by formal education and work experience. The school system provides signals, for example grades, $g$, that are public knowledge and are imperfectly correlated with ability, $g_{i, t}=h_{i, t}+u_{\mathrm{t}}$, where $u_{\mathrm{t}}$ is a random noise variable. The observed worker's productivity over time $y_{i, t}=h_{i, t}+v_{t}$ will also be correlated with ability. To simplify the exposition, we assume that the noise variables of the two signals, education and work experience, are related in the form of $u_{\mathrm{t}}$ $=v_{\mathrm{t}} / \varphi$. The parameter $\varphi$ is positive and finite and accounts for possible differences in the information content of signals about the hidden ability of the worker provided by the years of schooling, compared with the information content of signals coming from work experience. A value of $\varphi$ greater than (lower than or equal to) 1 implies that the signals from formal education are more (less or equally) informative than those coming from work experience.

\footnotetext{
${ }^{4}$ Further discussion can be found in Ortín-Ángel and Salas-Fumás (2002), Garicano (2000) or Gibbons and Waldman (1999a).
} 
iv) Workers' wages

Employers update their beliefs about the expected ability of worker $i$ taking into account all public information accumulated until $t, I_{i, t}: \mathrm{E}\left(h_{t} / \mathrm{I}_{i, t}\right)$, where $h_{t}$ is a random variable that captures the distribution of beliefs about workers' abilities after $t$ periods of time.

We assume that, as a result of competition, the current wage will be equal to expected productivity conditional to the information accumulated about the worker throughout her life ${ }^{5}, \mathrm{Ln} w_{i}=\mathrm{E}\left(\left(y_{, A}=h_{A}+v_{A}\right) / \mathrm{I}_{i, A}\right)=\mathrm{E}\left(h_{A} / \mathrm{I}_{i, A}\right)$, where $A$ is the age of the worker. Sometimes the age of the worker when she is promoted to hierarchical level $L$, defined by $P$, is also known. According to such models as Gibbons and Waldman (1999a), the promotion will occur when the worker's estimated ability is equal to or exceeds the minimum level required for the new job. In those models, time is a discrete variable. Under continuous time, one would expect managers that have just been promoted to have the minimum ability required for that hierarchical level. Assuming that workers will be promoted to level $L$ when their expected ability is equal to the minimum required for that job position, we get $m_{L}=\mathrm{E}\left(\left(y_{P}=h_{P}+v_{P}\right) / \mathrm{I}_{i, P}\right)=\mathrm{E}\left(h_{P} /\right.$ $\left.\mathrm{I}_{i, P}\right)$.

\subsection{Empirical implications}

This section derives the distribution of wages conditional on information most often available about workers in empirical analyses: age, $A$, years of schooling, $S$, hierarchical position, $H_{L}$ and job tenure, $J$. We distinguish between situations where innate ability is public knowledge and situations where it is private knowledge.

\footnotetext{
${ }^{5}$ We express wages and productivity in logs because the distribution of wages is empirically log normal.
} 


\section{i) A human capital model}

Given a linear production function of ability $h_{i, A}=a_{i}+\sum_{t=1}^{A} r_{t}$ and perfect information, $\sigma_{V}^{2}=0$, the ability of a worker with $S$ periods of schooling ${ }^{6}$ and $E$ periods of work experience is public knowledge and will be given by: $h_{i, A}=a_{i}+c_{1} S+c_{2} E$. Since everybody knows the worker's innate ability, we must get $\operatorname{Ln} w_{i}=\mathrm{E}\left(h_{A} / \mathrm{I}_{i, A}\right)=$ $h_{i, A}=a_{i}+c_{1} S+c_{2} E$. On the other hand, given that workers are assigned to hierarchical level $L$ when they accumulate an expected ability of $m_{L}=\mathrm{E}\left(h_{P} / \mathrm{I}_{i, P}\right)=h_{i, P}=a_{i}+c_{1} S+$ $c_{2} P$, compensation can also be expressed as: $\operatorname{Ln} w_{i}=m_{L}+c_{2} J$, where $J=E-P$ is the tenure of the current job position.

Given the observed distribution of the $\log$ of wages, Ln $w$, in a sample of workers with known ages and years of schooling, expected wages and variance of wages conditional to age and years of schooling, $X_{i}=\left(S_{i}, A_{i}\right)$, will be ${ }^{7}$ :

$$
\begin{aligned}
& \mathrm{E}\left(\operatorname{Ln} w / X_{i}\right)=\bar{a}+c_{1} S_{i}+c_{2}\left(A_{i}-S_{i}\right)=\bar{a}+\left(c_{1}-c_{2}\right) S_{i}+c_{2} A_{i} \\
& \operatorname{var}\left(\operatorname{Ln} w / X_{i}\right)=\sigma_{a}{ }^{2}
\end{aligned}
$$

When information about workers' job positions and job tenure is also available, $Z_{i}=\left(S_{i}, A_{i}, H_{L i}, J_{i}\right)$, the conditioned expected value and variance of salaries will be,

$$
\begin{aligned}
& \mathrm{E}\left(\operatorname{Ln} w / Z_{i}\right)=m_{\mathrm{L}}+c_{2} J_{i} \\
& \operatorname{var}\left(\operatorname{Ln} w / Z_{i}\right)=0
\end{aligned}
$$

\footnotetext{
${ }^{6} \mathrm{We}$ assume that the years of schooling are uncorrelated with innate ability for simplicity of exposition.

${ }^{7}$ Mincer (1974) argues that $c_{2}$ will not be constant over time and that older workers will spend less time in the training than younger ones. The results below can easily be extended to this case which implies a concave increasing relation between wage and experience. We account for this in the empirical formulation of the model.
} 
Therefore, in a world of perfect information, the job position and job tenure of workers would provide sufficient statistics about their respective ability and no dispersion of salaries would be observed within job positions. Learning models study the dispersion of salaries when information about innate abilities is imperfect but can be improved over time.

\section{ii) A learning model}

The starting assumption is now $\sigma_{V}^{2}>0$. To simplify the exposition, first assume that formal education and job experience do not produce ability, $h_{i, t}=a_{i}$, although they can provide a signal that provides information about the innate ability of workers, the only attribute that determines differences in expected ability across workers.

Each period of expected innate ability of workers is updated using new information in terms of on-the-job performance or schooling results. Following DeGroot (1970), efficient use of new information in updating the innate ability of worker $i$ of age $A$ implies a compensation equation of the form,

$$
\operatorname{Ln} w_{i}=\mathrm{E}\left(h_{A} / \mathrm{I}_{i, A}\right)=\mathrm{E}\left(a / \mathrm{I}_{i, A}\right)=\bar{a}+\left(\rho_{A} \sigma_{a} / \sigma_{A}\right)\left(I_{i, A}-\bar{a}\right)
$$

where $I_{i, A}=\left(\sum_{t=1}^{S}\left(\varphi^{2} g_{i, t}\right)+\sum_{t=S+1}^{A} y_{i, t}\right) /\left(A+\left(\varphi^{2}-1\right) S\right)$ is the weighted average of signals of ability collected for worker $i$. This variable is the realization for worker $i$ of the random variable $I_{A}=a+\left(\sum_{t=1}^{S}\left(\varphi v_{t}\right)+\sum_{t=S+1}^{A} v_{t}\right) /\left(A+\left(\varphi^{2}-1\right) S\right)$, defined for the population of workers of age $A$. The random variable $I_{A}$ has the expected value $\bar{a}$, variance ${ }^{8} \sigma_{A}^{2}=$

\footnotetext{
${ }^{8}$ The result is the same as in Murphy (1986) for the particular case of $\varphi=1$, which implies that work experience and formal education provide the same information on hidden worker's ability.
} 
$\sigma_{a}^{2}+\frac{\sigma_{v}^{2}}{A+\left(\varphi^{2}-1\right) S}$, and correlation coefficient $\rho_{A}$ with the distribution of shared beliefs about hidden ability $a$ so that ${ }^{9} \rho_{A}{ }^{2}=\sigma_{a}^{2} / \sigma_{A}^{2}$.

If $\varphi>1$, that is, when the signals from years of education create less noise than signals from years of work experience, it follows that variance $\sigma^{2}{ }_{A}$ (correlation coefficient $\rho_{A}$ ) decreases (increases) with the age of the workers, $\partial \sigma_{A}{ }^{2} / \partial A<0$, and with years of schooling, $\partial \sigma_{A}^{2} / \partial S<0$.

We can now model the process of learning about innate abilities after workers have been promoted. Define $k_{L, P}$ as the distribution of the abilities of workers promoted to hierarchical level $L$ when they are $P$ years old. Therefore, $k_{L, P}=\left(a / \mathrm{I}_{i, P}\right)$. This variable is distributed as normal with a mean equal to the estimated ability at the time of promotion, $m_{L}=\mathrm{E}\left(a / \mathrm{I}_{i, P}\right)$, and variance, $\sigma_{k}{ }^{2}=\operatorname{var}\left(a / \mathrm{I}_{i, P}\right)=\sigma_{a}^{2}\left(1-\rho_{A=P}^{2}\right)=$ $\frac{1}{\frac{P+\left(\varphi^{2}-1\right) S}{\sigma_{V}^{2}}+\frac{1}{\sigma_{a}^{2}}}$, (DeGroot, 1970). This variance is an inverse measure of the precision by which the ability of the worker has been estimated at the time of promotion. Variance $\sigma_{k}{ }^{2}$ decreases with the time needed to get the promotion, $\partial \sigma_{k}^{2} / \partial P$ $<0$, and with years of schooling, $\partial \sigma_{k}^{2} / \partial S<0$, if $\varphi>1$.

After promotion, new information is accumulated, $\Delta I_{i, J}=\left(\sum_{t=P+1}^{A} y_{t} / J\right)$, and expected abilities are updated. As a consequence, the current wage of a worker of age $A$ promoted to hierarchical level $L$ at age $P=A-J$, is given by :

$$
\operatorname{Ln} w_{i}=\mathrm{E}\left(h_{A} / \mathrm{I}_{i, A}\right)=\mathrm{E}\left(a / \mathrm{I}_{i, A}\right)=\mathrm{E}\left(k_{L, P} / \Delta I_{i, J}\right)=m_{L}+\left(\rho_{\Delta \mathrm{I}} \sigma_{k} / \sigma_{\Delta \mathrm{I}}\right)\left(\Delta I_{i, J}-m_{L}\right)
$$

\footnotetext{
${ }^{9}$ Note that $\operatorname{var}\left(I_{A^{-}} a\right)=\sigma_{\mathrm{A}}^{2}-\sigma_{a}^{2}=\sigma_{a}{ }^{2}+\sigma_{A}^{2}-2 \operatorname{cov}\left(a, I_{A}\right)$. The result is the same as in Murphy (1986) for the particular case of $\varphi=1$.
} 
Where $\rho_{\Delta \mathrm{I}}$ is the correlation coefficient between $\Delta I_{J}$, the variable that captures the distribution of $\Delta I_{i, J}$ among workers promoted at the same time to hierarchical level ${ }^{10}$, and the information existing at the time of promotion $k_{\mathrm{L}, P}$, with $\rho_{\Delta \mathrm{I}}{ }^{2}=\left(1 /\left(1+\sigma_{V}^{2} /\left(J \sigma_{k}^{2}\right)\right)\right.$.

Like before, $\mathrm{Ln} w$ is the random variable that captures the distribution of the logarithm of wages among the population of workers. If age and years of schooling are the only observable attributes of the workers in the sample, the expected wage and the variance of wages conditional on $X_{i}=\left(S_{i}, A_{i}\right)$ will be:

$$
\begin{aligned}
& \mathrm{E}\left(\operatorname{Ln} w / X_{i}\right)=\bar{a} \\
& \operatorname{var}\left(\operatorname{Ln} w / X_{i}\right)=\sigma_{a}{ }^{2} \rho_{A}^{2}=\sigma_{a}{ }^{2} \sigma_{a}{ }^{2} / \sigma_{A_{i}}^{2} .
\end{aligned}
$$

Notice that $\partial \operatorname{var}\left(\operatorname{Ln} w / X_{i}\right) / \partial A>0$. This means that the variance of compensation increases with age. The reason is that more information on the performance of the worker is available over time, which enables a refinement of beliefs about the value of her hidden abilities and true productivity, so workers are better sorted across jobs. Consequently, the individual productivity and salary of workers approximate more closely to the true distribution of hidden abilities in the working population. This is the widely recognized traditional result of learning models formalized by Harris and Holmstrom (1982).

The variance of wages increases more rapidly with a year of education than with a year of work experience, as long as $\varphi>1$, which occurs when signals generated during the schooling period offer greater information content than those provided by work experience. On the other hand, if experience provides more precise information about hidden abilities than schooling, $\varphi<1$, then one more year of work experience increases the variance of compensation by a higher amount than a year of schooling. Mincer's empirical evidence (1974) indicates that wage dispersion increases with years of

\footnotetext{
${ }^{10}$ Distributed as a normal with mean $m_{L}$ and variance $\sigma^{2}{ }_{\Delta \mathrm{I}}=\sigma_{k}{ }^{2}+\sigma_{V}^{2} / J$.
} 
schooling, so based on this evidence it appears that the hypothesis should be $\varphi>1$ and $\partial$ $\operatorname{var}\left(\operatorname{Ln} w / X_{i}\right) / \partial S>0$.

Assume now that, for each worker, information is also available about hierarchical positions and job tenure in the current job position $J$. The expected value and variance of the wages conditional on the information available, $Z_{i}=\left(S_{i}, A_{i}, H_{L}, J_{i}\right)$, will be,

$$
\begin{aligned}
& \mathrm{E}\left(\operatorname{Ln} w / Z_{i}\right)=m_{L} \text { and } \\
& \operatorname{var}\left(\operatorname{Ln} w / Z_{i}\right)=\sigma_{k}^{2} \rho_{\Delta \mathrm{I}}{ }^{2} .
\end{aligned}
$$

For empirical purposes, the latter equation can be approximated by the firstorder terms of Taylor's expansion,

$$
\begin{aligned}
& \operatorname{var}\left(\operatorname{Ln} w / Z_{i}\right)=\sigma_{k}^{2} \rho_{\Delta \mathrm{I}}^{2} \approx \\
& \mu+\gamma_{1} S_{i}+\gamma_{3} A_{i}+\gamma_{4} J_{i}=\mu+\gamma_{1} S_{i}+\gamma_{3} P_{i}+\left(\gamma_{3}+\gamma_{4}\right) J_{i}
\end{aligned}
$$

The learning process continues after promotion, which implies that $\partial \rho_{\Delta I}{ }^{2} / \partial J>0$. Therefore, it is to be expected that var $\left(\operatorname{Ln} w / Z_{i}\right)$ will increase with the time spent in the current job position. Since $\partial \operatorname{var}\left(\operatorname{Ln} w / Z_{i}\right) / \partial J>0$, the empirical prediction for the parameters of the approximation function is that $\gamma_{3}+\gamma_{4}>0$. But the variance of compensation after $J$ years of job tenure also depends on the variance of the estimated ability at the time of promotion, $\sigma_{k}^{2}$. As indicated above, $\partial \sigma_{k}{ }^{2} / \partial P<0$ and $\partial \sigma_{k}{ }^{2} / \partial S<0$ if $\varphi>1$, because the greater the experience and education the more will have been learned about hidden ability at the time of entering the last job and, consequently, less can be learned in the future. Therefore, the additional empirical predictions are $\gamma_{3}<0$ and $\gamma_{1}<0$. 
iii) Empirical evidence and alternative explanations of compensation dispersion within jobs

Previous empirical research has found a positive association between human capital variables and compensation, with and without controlling for job positions. Since education and experience come into decisions about job assignments, introducing these variables into a compensation model reduces the explanatory power of human capital variables (Ortín-Ángel and Salas Fumàs, 2002).

There is also evidence of a positive association between wage dispersion and schooling or work experience ${ }^{11}$. The evidence is consistent with the way employers learn about the hidden abilities of workers over time, so workers are progressively sorted into jobs whose productivity closely matches the distribution of abilities in the respective cohort. This paper investigates the implications of learning theory on the relationship between within job compensation dispersion and human capital variables, such as experience and education. The research is relevant because learning models provide theoretical support for models of career concerns within the broader field of internal labour markets, (Holmstrom, 1982; Gibbons and Murphy, 1992; Auriol et al., 2002 and Andersson, 2002). Since most of the regularities found in previous empirical work can also be explained by human capital models under perfect information, $\sigma_{V}^{2}=0$, evidence in support of learning models based upon within-job compensation dispersion and its determinants will further validate the use of learning models to study career concerns and internal labour markets.

As in Gibbons and Waldman (1999a), consider a situation where the abilities accumulated over time increase with innate ability. In our linear production function of ability, this would imply, $h_{i, A}=f\left(a_{i}, r_{1}, \ldots, r_{A}\right)=a_{i}+\sum_{t=1}^{A} r_{t} a_{i}=a_{i}+c_{1} a_{i} S+c_{2} a_{i} E=$

${ }^{11}$ See, e.g., Mincer (1974). 
Ln $w_{i}$. That is the marginal contribution to productivity and salaries of one year of education or experience is higher for more able workers.

Given the general wage equation $\operatorname{Ln} w=a+c_{1} a S+c_{2} a E=m_{L}+c_{2} a J$ the expected wage and variance from the wage distribution in the population of workers, conditioned on age and schooling, $X_{i}=\left(S_{i}, A_{i}\right)$, are given as:

$$
\begin{aligned}
& \mathrm{E}\left(\operatorname{Ln} w / X_{i}\right)=\bar{a}+c_{1} \bar{a} S_{i}+c_{2} \bar{a}\left(A_{i-} S_{i}\right)=\bar{a}+\left(c_{1-} c_{2}\right) \bar{a} S_{i}+c_{2} \bar{a} A_{i} \quad \text { and } \\
& \operatorname{var}\left(\operatorname{Ln} w / \mathrm{X}_{\mathrm{i}}\right)=\left(1+\left(c_{1}-c_{2}\right) S_{i}+c_{2} A_{i}\right)^{2} \sigma_{a}^{2} .
\end{aligned}
$$

If information is also available for job positions and tenure, $Z_{i}=\left(S_{i}, A_{i}, H_{L i}, J_{i}\right)$, then the expected wage and variance will be:

$$
\begin{aligned}
& \mathrm{E}\left(\operatorname{Ln} w / Z_{i}\right)=m_{L}+c_{2} \bar{a} J_{i} \\
& \operatorname{var}\left(\operatorname{Ln} w / Z_{i}\right)=\left(c_{2} J_{\mathrm{i}}\right)^{2} \sigma_{a}^{2}
\end{aligned}
$$

When there are cross effects between innate ability and work experience, the variance of compensation will also increase with job tenure in absence of learning. Several papers report a positive association between variance of compensation and job tenure (Murphy, 1986; Foster and Rosenzweig, 1993; Baker et al., 1994 and Poppo and Weigelt, 2000) and explain it as a consequence of learning. But we have just shown that this evidence can be explained in at least two ways, one from learning theory and the other from the interaction between innate and acquired abilities ${ }^{12}$. If we find empirical support for the predictions derived before compensation dispersion (i) decreases with work experience in previous jobs, $\partial \operatorname{var}\left(w / Z_{i}\right) / \partial P<0$; and (ii) increases with tenure of

\footnotetext{
12 Other tests conducted with panel data (e.g. Farber and Gibbons,1996; Altonji and Pierret, 2001; Bauer and Haisken-DeNew, 2001) are subject to the same doubts about the true causes behind their empirical evidence. In addition, it could happen that the proxies used for innate abilities (AFQT test, father's education, etc.) can be correlated with unobserved investments in on-the-job training by workers and/or with other proxies of innate abilities used by employers when the worker is hired.
} 
the current job, $\partial \operatorname{var}\left(w / Z_{i}\right) / \partial J>0$ we have a more robust test of learning theory than if we just find support for prediction (ii), since this has alternative explanations.

Moreover, the predictions $\partial \operatorname{var}\left(w / Z_{i}\right) / \partial P<0$ and $\partial \operatorname{var}\left(w / Z_{i}\right) / \partial J>0$ could also be explained by the hypothesis of cross effects between innate and acquired ability together with the additional assumption that the periodical increase in abilities from work experience, $c_{2}$, is a decreasing function of age because, for example, on-the-job training decreases as a worker gets older. If this was the case, we would get another empirical prediction. Between job compensation dispersion $\operatorname{var}\left(\operatorname{Ln} w / X_{i}\right)$ will increase at a higher rate with experience in previous jobs than with tenure of the current one. So, we find a possible alternative explanation for our main predictions of learning theory that can be empirically tested by models of between-job compensation dispersion.

\section{EMPIRICAL ANALYSIS}

\subsection{Sample and variables}

The implications of learning models will be tested using cross-section data from a sample of Spanish managers provided to us by ICSA, a consulting firm ${ }^{13}$. The data was obtained by means of a questionnaire that firms answered on a voluntary basis in 1990 , 1991 and 1992. However, for reasons of confidentiality, we have no access to the identity of the firms or managers and, therefore, do not know whether managers or firms are repeated in different years, or whether managers have been internally promoted or externally recruited. Given this limitation, the observations for the three years were pooled together, resulting in a total number of 9,694 top and middle managers working for 669 different firms. The sample is similar to that used by Leonard (1990) and Gerhart and Milkovich (1990) for managers of North American firms. Firms belonging to all sectors of economic activity except agriculture are included, but the sample is biased towards relatively large firms, even though the

\footnotetext{
${ }^{13}$ For a more detailed description of the data see Ortín-Ángel and Salas Fumàs $(1998,2002)$.
} 
average size of the firms in our sample (569 employees and \$138.5 million turnover) is much smaller than in the samples of American firms (around 30,000 employees and \$5 billion turnover).

The questionnaire collects information for a sample of middle and top managers from each firm. Information is available about the characteristics of the firms, such as size and industry; about personal characteristics of managers, such as age, formal education, years in the current job; and about job positions, such as salary, hierarchical level and functional area. Table 1 summarizes the descriptive statistics for each of the variables in the database that are relevant to our analysis.

\section{<INSERT TABLE 1>}

Salary $(w)$ is the total annual amount of cash received by the executives in the form of base salary and variable compensation. Other information about the executive's ownership of shares and/or stock options is not available, but such forms of remuneration are unusual for Spanish firms ${ }^{14}$.

Level of Formal Education is a categorical variable with three mutually exclusive values indicating the highest educational grade obtained by the manager: "titulados superiores" (SUP), "titulados medios" (MED), and "others" (OTH). A dummy was created for each of the categories with a value of "one" when the manager belongs to the category referred to, and "zero" otherwise. The "titulado superior" degree is usually obtained after 17 years of education, and the "titulado medio" degree after 15 years. In the "other" category are those executives with educational degrees that require less than 15 years of education. The figures in Table 1 show, as would be expected for a sample of managers, relatively high levels of education. About 41 percent of the executives had accumulated more than 17 years of education $(S U P) ; 37$ percent of them had between 15 and 17 years of education $(M E D)$; managers with less than 15 years of

\footnotetext{
${ }^{14}$ Information from other sources, for example, Murphy (1999 p. 2495), confirms this.
} 
education represent only 22 percent of the sample. The percentages for the general population were 3.4, 4.3 and 92.3, respectively, when the sample was collected.

Assuming that entry into the labour market takes place after the completion of formal education and that all the managers began their schooling at the mandatory age, the age of the manager $(A)$ will serve as an appropriate measure of total work experience. The sample also contains information about the number of years that the managers have been in their current job positions (tenure on the job, $J$ ); variable $J$ is a proxy of job-specific experience. The average age of the managers in our sample is 43 years, having attained their current job position at the age of 36 and having held that position for 7 years.

Job position is described by the hierarchical level and functional area. This information is provided by the firms when they answer the survey, classifying executives according to different predetermined job positions: "General Manager" $\left(H_{l}\right)$, “Division Manager" $\left(H_{2}\right)$, "Functional Director" $\left(H_{3}\right)$, and three levels below the functional director $\left(H_{4}, H_{5}\right.$, and $\left.H_{6}\right)$. The functional areas are "Production" (PROD), "Marketing" $(M A R K)$, and "Administration" $(A D M)$. The "Administration" category includes all functional areas apart from production and marketing, but executives in this category are overwhelmingly human resources and financial managers. For all of these categories, a dummy variable was created, with a value of "one" when the manager belongs to the category, and "zero" otherwise. We have thus generated six dummies referring to hierarchical positions, $\left(H_{1}, H_{2}, H_{3}, H_{4}, H_{5}\right.$, and $\left.H_{6}\right)$ and three dummies referring to the functional area (PROD, MARK, and $A D M)$.

The sample of managers is unevenly distributed across job positions and some of these positions are probably underrepresented. Table 1 indicates that 7 percent of managers (669) are CEO's, which coincides with the number of firms in the sample. There are only 90 Division Managers $\left(H_{l}\right)$ (2 percent), reflecting the fact that most of the firms in the sample are relatively small and do not have this job position. The largest percentages of managers are concentrated in the first and second levels of the functional areas $\left(H_{3}\right.$ and $\left.H_{4}\right), 30$ and 43 percent respectively, while in the third and fourth 
functional levels $\left(H_{5}\right.$ and $\left.H_{6}\right)$, the total number of managers is only 15 and 4 percent, respectively. The functional areas (PROD, MARK, and $A D M)$ are evenly represented, with around 30 percent of the managers in each.

Table 2 provides additional descriptive statistics about the average and standard deviation of total managerial compensation $(w)$ and its logarithm ( $\operatorname{Ln} w)$ broken down into formal education, age, hierarchical levels and functional areas. As expected, average compensation increases with formal education, experience, and hierarchical level, and is higher in the marketing area than in production or administration. The standard deviation in each category of the variables increases with the mean. The pattern of means and standard deviations does not change substantially when compensation is expressed in logarithms.

\section{<INSERT TABLE 2>}

\subsection{Econometric models}

There are two econometric models to be estimated: one where the dependent variable is expected conditional compensation and the other where the dependent variable is conditional variance of compensation. The two models correspond first to salaries across job positions and, then, to within-job positions. Expected productivity and compensation are mainly determined by human capital variables. The model allows for marginally decreasing returns in experience, often validated by empirical human capital models, so we include age $A$ and age squared $A^{2}$ as explanatory variables with the expected coefficient positive for the former and negative for the later. Job tenure $J$ is included as an explanatory variable to allow for job specific human capital acquired during the time the manager has been in the current job.

We also add, as an explanatory variable, the cross effect of age and job tenure $A J$. There are two potential explanations for the marginally decreasing returns of work experience (negative coefficient of $A^{2}$ ): that on-the-job training investments decrease as workers get older and the remaining working life gets shorter; and that workers with lower innate ability take a longer time to reach the job position they are in. A negative 
estimated coefficient for $A^{2}$ is consistent with the two explanations. If the estimated coefficient of $A J$ is also negative, the evidence would confirm the interaction between innate and acquired ability postulated by Gibbons and Waldman (1999a). This occurs because of our assumption that innate ability can be approximated in an inverse way by the age of the manager once we control for job tenure (more time until promotion to the current position).

Models of compensation levels and variance across jobs positions are formulated as $^{15}$ :

$E\left(L n w / X_{i}\right)=\sum_{j=1}^{669} \alpha_{j} \operatorname{FIRM}_{j, i}+\beta_{1} S U P+\beta_{2} M E D+\beta_{3} A_{i}+\beta_{4} J_{i}+\beta_{5} A_{i} J_{i}+\beta_{6} A_{i}{ }^{2}+\varepsilon_{i}$

$\operatorname{var}\left(\operatorname{Ln} w / X_{i}\right)=\operatorname{Ln} \sigma_{\varepsilon}^{2}=\sum_{j=1}^{669} \mu_{j} \operatorname{FIRM}_{j, i}+\gamma_{1} S U P_{i}+\gamma_{2} M E D_{i}+\gamma_{3} A_{i}+\gamma_{4} J_{i}$

The dummy variables $\operatorname{FIRM}_{j, i}$ take the value of 1 if the manager works for firm $\mathrm{j}$ and 0 otherwise. They control for unobserved characteristics common to all managers that work in the same firm.

We expect $\beta_{1}>\beta_{2}>0, \beta_{3}>0$. These predictions come from traditional human capital theories, which establish that productivity and salaries increase with formal education and work experience. When job tenure provides managers with specific human capital (Becker, 1964), compensation will increase with job tenure after controlling for age, so we expect $\beta_{4}>0$. If marginal productivity of experience decreases over time because on-the-job training decreases as workers get older (Mincer, 1974), then $\beta_{6}<0$. If decreasing marginal returns to experience respond to

15 Take note that $\mathrm{A}=\mathrm{P}+\mathrm{J}$, so: $\beta_{5} A_{i} J_{i}+\beta_{7} J_{i}{ }^{2}=\beta_{5} P_{i} J_{i}+\left(\beta_{7}+\beta_{5}\right) J_{i}{ }^{2}$. The specification finally used assumes that $\beta_{7}=0$, an assumption not rejected by the data. 
interactions between innate and acquired abilities, in addition to decreasing investment in training over time, then $\beta_{5}<0{ }^{16}$.

Although model (1) is often justified by human capital arguments such as those given in previous paragraphs, the expected sign of the coefficients of the age and education variables can be justified by alternative theories, such as learning and signalling theories. Harris and Holmstrom (1982) show that imprecise estimations of innate abilities introduce risks in the compensation of managers. The employment relation will be more efficient if employers insure risk averse managers against these risks and one way to do so is to offer a salary scheme that increases with age and formal education, even if productivity remains unchanged. On the other hand, Spence (1976) shows that when education can be a signal of hidden ability, a positive correlation is expected between compensation and education even when formal education does not increase acquired human capital. The conditional variance model (2) can help in sorting out potential explanations since the predicted results from learning models are difficult to reconcile with human capital theories.

From the learning model it is expected that the conditioned compensation variance will increase with age, $\gamma_{3}>0$, and if formal education provides more precise information about innate abilities than work experience $(\varphi>1)$ then $\gamma_{1}>\gamma_{2}>0$. Finally, assuming complementarities between innate and acquired ability (Gibbons and Waldman,1999a) if abilities derived from work experience increase at a decreasing rate over time, then $\gamma_{4}<0$.

\footnotetext{
${ }^{16}$ Notice that since $\mathrm{A}=\mathrm{P}+\mathrm{J}, \beta_{6} A^{2}=\beta_{6}\left(P^{2}+2 A J-J^{2}\right)$. Therefore, the variable age squared also captures the cross effect $A J$ with expected negative sign. If $A^{2}$ is not included as an explanatory variable, a negative coefficient on $A J$ has an ambiguous interpretation since it can indicate either decreasing returns because training investments decrease with age, or that innate abilities interact with acquired ones in determining productivity.
} 
The within-job models of expected value and variance of salaries are formulated as follows:

$$
\begin{aligned}
& E\left(L n w / Z_{i}\right)=\sum_{j=1}^{669} \alpha_{j} F I R M_{j, i}+\beta_{1} S U P_{i}+\beta_{2} M E D_{i}+\beta_{3} A_{i}+\beta_{4} J_{i}+\beta_{5} A_{i} J_{i}+\beta_{6} A_{i}^{2}+\sum_{L=1}^{5} \beta_{7, L} H_{L i}+\beta_{8, l} P R O D_{i}+\beta_{8,2} M A R K_{i}+\varepsilon_{1} \text { (3) } \\
& \operatorname{var}\left(\operatorname{Ln} w / Z_{i}\right)=L n \sigma_{\varepsilon}^{2}=\sum_{j=1}^{669} \mu_{j} F I R M_{j, i}+\gamma_{I} S U P_{i}+\gamma_{2} M E D_{i}+\gamma_{3} A_{i}+\gamma_{4} J_{i}+\sum_{L=1}^{5} \gamma_{5, L} H_{L i}+\gamma_{6, l} I P R O D_{i}+\gamma_{6,2} M A R K_{i}
\end{aligned}
$$

If job positions provide information about the estimated abilities of managers then $\beta_{1}, \beta_{2}, \beta_{3}$ and $\beta_{6}$ in (3) should be close to zero, according to traditional human capital theory. Learning and insurance considerations imply that these coefficients will be positive even after controlling for job positions. If human capital accumulation continues after promotion we expect $\beta_{4}>0$. If innate and acquired human capital interact in the way indicated above then we expect $\beta_{5}<0$. We expect $\beta_{7,1}>$ $\beta_{7,2}>\beta_{7,3}>\beta_{7,4}>\beta_{7,5}>0$ since level 1 refers to the top level of the hierarchy ${ }^{17}$.

According to the learning theory presented in section 2, we expect those managers whose ability has been better assessed at promotion to have less future salary dispersion, so $\gamma_{1}<\gamma_{2}<0, \gamma_{3}<0$, the reverse sign to that predicted by model (2), which explains across job dispersion. Notice that the manager's age, $A$, will be the sum of experience before entering the current job $P$ and job tenure, $J, A=P+J$. Thus, the net effects of job tenure on the error variance, given previous work experience, will be measured by $\gamma_{4}+\gamma_{3}$. If the firm continues to learn after the manager is promoted we expect $\gamma_{4}+\gamma_{3}>0$. Learning theories predict a negative value for coefficient $\gamma_{3}$ and a positive value for $\gamma_{4}$ in Equation (4). On the other hand, we saw earlier that alternative

17 The specification used controls for differences in the number of hierarchical levels and in the productivity of the last hierarchical level observed given that $\beta_{5, \mathrm{~L}}=m_{L}-m_{6}$, and firm specific effects capture differences in $m_{6}$ among firms. 
theories predict $\gamma_{4}>0$ in Equation (2). We can therefore compare theories through the estimated coefficients of Equations (2) and (4).

\subsection{Results}

Equations (1) and (2) define an econometric model with multiplicative heteroskedasticity. The proper estimation method for these models is presented in Harvey (1976) and in Greene (1998, Ch. 12). Table 3 presents the results of this estimation. The Breusch-Pagan test of heteroskedasticity rejects the null hypothesis of constant variance for the error terms of Equation (1), which does not explicitly model the variance of the error term. The fact that the log-likelihood ratio test (Log-L (wages equation and $\sigma^{2}$ equation)) is statistically significant indicates that the variables in Equation (2) explain part of the variability of the error terms $\varepsilon_{i}$ (variance). The null hypothesis that firms' fixed effects are all zero is rejected at high levels of statistical significance $^{18}$.

\section{<INSERT TABLE 3>}

The estimation of (1) shows that those managers with a higher university degree earn, on average, 48 percent higher salaries than those with no university degree, $\left(\hat{\beta}_{1}=\right.$ 0.48), and 28 percent higher salaries than those with a lower university degree $\left(\hat{\beta}_{1}-\hat{\beta}_{2}=0.28\right)$. At the same time, managers with a lower university degree earn 20 percent more than managers with no university degree, $\hat{\beta}_{2}=0.20$. The hypothesis that compensation increases with years of formal education, as human capital theories predict, cannot be rejected.

\footnotetext{
${ }^{18}$ Since we can not identify the managers repeated along the three sample years it is impossible to control for managers' fixed effects. To check for the robustness of the results we have estimated the model year
} 
At the same time, $\hat{\beta}_{3}=6.65$ and $\hat{\beta}_{6}=-0.06$ are both significantly different from zero. One more year of general experience implies a $6.65 \%$ increase in compensation when the manager starts working, but the marginal return decreases by $0.12 \%$ per year of experience $\left(2 \hat{\beta}_{6}=-0.12\right)$. So, with 20 years of experience the marginal return is only $4.25 \%(6.65-2.4)$. Estimated coefficients $\hat{\beta}_{4}$ and $\hat{\beta}_{5}$ are not significantly different from zero, which implies that no evidence of job specific human capital and of interactions between innate and acquired abilities are detected.

The estimation of Equation (2) shows that the variance of the error term in Equation (1) increases with formal education and work experience, as the theory of learning predicts and previous empirical evidence has documented. Notice that $\hat{\gamma}_{1}=$ 0.53 and $\hat{\gamma}_{2}=0.05$, although only the former is statistically different from zero. The innate abilities of managers with a higher university degree are better assessed than those of managers with less formal education belonging to the same cohort. For a given level of formal education, the variance of the error term in Equation (1) also increases with the work experience of managers, $\hat{\gamma}_{3}=2.60$, confirming the prediction from learning theory that managers' innate abilities are better assessed when their work experience increases. Furthermore, this effect is greater (although only statistically significant at a level of 13\%) during the most recent years of work experience $\left(\hat{\gamma}_{4}=0.63\right)$. This would rule out the possibility that some of the observed evidence is explained by the fact that innate and acquired abilities interact (Gibbons and Waldman, 1999a) and work experience increases ability at a decreasing rate over time.

When information about job positions is included in the model, Equations (3) and (4) presented in the second column of Table 3, the results about the presence of heteroskedasticity are similar to those obtained without this information. In the new model, the general human capital variables still have positive and significant

by year and the main results shown in Table 3 are maintained so potential biases from having a set of managers repeated over time do not seem to be relevant. 
coefficients, but their values are lower than in Equation (1). The job position variables provide information about the human capital characteristics of workers that have been taken into account to decide on the allocation of workers to such positions. The additional explanation from learning theories (insurance) and signalling can not be ruled out as potential explanations of the evidence.

The hypothesis that the coefficient on the cross effect variable age and job tenure is equal to zero $\left(\hat{\beta}_{5}=0\right)$ is not rejected ${ }^{19}$. Job tenure now has a positive and statistically significant coefficient $\left(\hat{\beta}_{4}=0.45\right)$, which implies a marginal return on job specific capital of 0.45 . The fact that job specific human capital has a positive marginal return when we control for job positions and nil when we do not suggests that job tenure and hierarchical levels are correlated. For a given age, the number of years in the current job is higher for managers at lower hierarchical levels than for managers in higher ones. This suggests that once managers start being promoted they progress through the hierarchy at a relatively high speed. On the other hand, delays in being promoted increase the likelihood of the manager continuing in her current job for a longer period of time; Baker et. al. (1994) present evidence from one firm that supports this conclusion.

Equation (3) provides evidence of a convex relationship between compensation and hierarchical levels. Managers in the third hierarchical level of the functional area earn, on average, 22 percent more than managers in the fourth hierarchical level of the functional area $\left(\hat{\beta}_{7,5}=0.22\right)$, while CEOs earn, on average, 133 percent more than the lower-level managers included in the sample $\left(\hat{\beta}_{7,1}=1.33\right)$. The convexity in the relationship between compensation and hierarchical levels has been explained by tournament models, e.g., Lazear and Rosen (1981) and Rosen (1986), and detected in other empirical analyses (Cappelli and Cascio, 1991, and Leonard 1990).

\footnotetext{
${ }^{19}$ We reject the null hypothesis that $\beta_{6}$ is equal to zero. We are unable to tell, however whether this is due to decreasing marginal return from experience or cross effects between innate and acquired abilities.
} 
Finally, note that managers in the production area earn, on average, around 2 percent more than managers in administration, $\hat{\beta}_{8,1}=0.02$, and 11 percent less than managers in marketing $\left(\hat{\beta}_{8,2}-\hat{\beta}_{8,1}=0.11\right)$.

The bottom of the second column in Table 3 shows the results of the within-job compensation dispersion model. We find negative and statistically significant coefficients for the variables education, $\hat{\gamma}_{1}=-0.31, \hat{\gamma}_{2}=-0.23$, and age, $\hat{\gamma}_{3}=-0.99$. However, dispersion increases with job tenure, $\hat{\gamma}_{4}=1.35$, which is significantly different from zero. The variance of the error term in (3) decreases with the amount of information available about the managers at the time of promotion to the current job, as the theory predicts. After they are assigned to their current job, the evaluation of a manager's abilities continues. The combined effect of total work experience in withinjob compensation dispersion is positive $\hat{\gamma}_{4}+\hat{\gamma}_{3}=0.36$, but with a high standard error of the estimate, so the null hypothesis of being equal to zero is rejected at a $\mathrm{p}$ value of 0.32 .

The empirical evidence also shows that the variance of the error term in the compensation equation increases at the top of the hierarchy and is lower in production than in other functional areas: Managers' abilities may be more difficult to evaluate at upper-hierarchical levels and in production than in other areas of the organization.

\section{DISCUSSION AND IMPLICATIONS}

\subsection{Main implications}

Learning about the hidden abilities of employees has been postulated as a possible explanation for the heteroskedasticity observed in empirical models of compensation (Harris and Holmstrom, 1982). For example, the evidence that the variance of the error term of the model increases with years of formal education and work experience, formerly detected by Mincer (1974), would be consistent with the 
prediction from learning models that formal education and experience improve the information available to firms about managers' ability and that there will be better matching between employees' abilities and jobs over time. Equation (2), estimated with data from a sample of Spanish managers assigned to different job positions, gives similar results and confirms that conditional compensation dispersion increases with formal education and work experience when the compensation equation does not control for job positions.

Furthermore, this conditional compensation dispersion is greater for those managers that, controlling for age, have more years of education. Harris and Holmstrom (1982) interpret this result as a consequence of the signalling properties of education. Spence (1976) argued that education could be used to signal innate ability. A tentative explanation, proposed in this paper, is that we should expect higher compensation dispersion for more educated workers if higher education is a more effective way of signalling hidden abilities than work experience. Otherwise, people would prefer to take a job earlier on in life so that employers could learn about their hidden abilities from work experience. Further in-depth work is needed to sort out these alternative explanations of the empirical evidence.

Equation (2) tests the learning model on the basis of its predictions of the determinants of conditional compensation dispersion. There are, however, other possible explanations for the results highlighted in the theory section of the paper, which come from traditional human capital theory. For example, it may be that the return on investment in job training decreases over time in situations where innate ability and acquired human capital interact in determining the workers' productivity. In that case, compensation dispersion is expected to increase per additional year of job tenure at a lower rate than per year of general experience $\left(\gamma_{4}<0\right.$ in Equation (1)). The data rejects this hypothesis and learning models explain the evidence for compensation dispersion in a more consistent way than alternative models.

All managers within a hierarchical position will have an estimated ability at the time of being promoted to the job equal to that demanded for that position. However, 
estimated ability at the time of promotion may vary in terms of precision if hidden ability is garnered from the information available about each manager, and this information varies between them. Learning will continue in the new job, but the information content of this learning is expected to be lower for managers that started the job with more precision in their estimated abilities. This implies that conditional compensation variance within the job will increase with job tenure (learning continues), and compensation variance (precision) will be lower (higher) for managers with a more formal education and more work experience at the time of the promotion (since there is more information available to estimate their ability). The multiplicative heteroskedasticity formulation (Harvey, 1976) led us to test, and in our case (see Equation 4) confirm, these predictions. As in Murphy (1986) and Baker et al. (1994), compensation variation increases with job tenure, but the multivariate analysis of the error variance also led us to verify that it decreases with formal education and work experience prior to the current job. These results cannot be explained by conventional human capital models and provide a more robust test of learning.

\subsection{Other implications}

Estimations of Equations (1) \& (3) in Table 3 show results similar to those found in the existing literature but also additional ones that deserve mention.

The introduction of job positions to explain differences in managerial compensation could make the information about the characteristics of the manager irrelevant in determining compensation. After all, holding a particular job position implies having the ability required for the job. Empirical evidence from the same database confirms that human capital variables explain 50 percent of the compensation differences between hierarchical levels (Ortín-Ángel and Salas-Fumàs, 2002). As shown in Table 3, controlling for job positions substantially reduces the effects of education and general work experience on compensation (by 60 percent). Although intra-job heterogeneity and differences in human capital can not be ruled out as potential 
explanations, the insurance effects predicted by the learning models may be an alternative explanation for the observed positive effect of experience and education in compensation after controlling for job positions (Harris and Holmstrom, 1982, Theorem $6)$.

Another important result is that, controlling for job position, the effect of job tenure on compensation becomes statistically significant and positive. Managers acquire specific human capital with on-the-job experience (Topel, 1991), which can only be properly evaluated when job positions are incorporated into the model. The reason for this, along with learning about hidden ability, is that job tenure is not independent of job positions. There is evidence in the data that job tenure is higher for lower hierarchical positions than for higher ones. Longer job tenure is associated with lower estimated innate ability, since those managers whose ability is believed to be higher are promoted faster to higher hierarchical positions.

Promotion to a higher hierarchical position may be the result of an optimal assignment of abilities to jobs or the consequence of the incentives established by the firms, as in tournament models (Lazear and Rosen, 1981). The observed "convexity" between hierarchical position and compensation, together with the fact that job positions have more explanatory power for differences in compensation than do human capital variables, is interpreted as evidence of tournament-type explanations for the salary differences between hierarchical positions. Nevertheless, this explanation ignores possible differences in productivity between hierarchical levels due to differences in information about innate ability not captured by such observable variables as education and experience. Baker et al. (1994) provide evidence from a single firm that managers promoted to higher job positions receive higher than average salary increases, but these increases are lower than the differences in average compensation between levels.

Gibbons and Waldman (1999a) explain the results in Baker et al. through the argument that managers who have held their job positions for a longer period of time will have acquired more human capital, and on-the-job human capital acquisition increases with the innate ability of the managers. If managers who need less work 
experience to reach their current hierarchical position are also those with higher innate abilities the marginal return from one year of job tenure should decrease with the age of the manager. We find evidence in support of the hypothesis that the marginal return of job tenure decreases with the age of the manager, estimated $\beta_{6}<0$, but we can not rule out the alternative explanation that investment in on the job training decreases as managers get older; the reason being that we do not reject $\beta_{5}=0$.

Finally, the evidence suggests that better assignment of managers to job positions because of learning competes with incentive/tournament reasons for explaining the promotion of managers to higher-level jobs, something that has often been ignored in previous empirical tests of tournament models (Conyon et al., 2001, Eriksson, 1999).

\section{CONCLUSION}

The empirical results of the paper confirm that the assignment of a manager to a particular job reveals the information employers have about the manager's hidden ability at the time of the assignment. The fact that learning continues after the assignment suggests that the assignment is made with imperfect information. This conclusion agrees with previous explanations for why compensation dispersion increases with job tenure (Murphy, 1986; Foster and Rosenzweig, 1993; Baker et al., 1994; Poppo and Weigelt, 2000), but our analysis expands on previous results in two ways.

It provides new testable predictions. If promotions are based on the estimated ability of the individual worker, workers assigned to a given hierarchical level at the same moment in time will have similar expected abilities, albeit assessed with different levels of precision. Consistent with learning models, there will be less to learn in the future for those workers whose ability has been better assessed at the time of promotion. The empirical prediction coming from this is that within-job compensation dispersion will be lower among those workers for whom the assessment of their ability was more imprecise at the time of the promotion. If work experience and formal education 
improve the precision of the assessment then within-job compensation dispersion should decrease with experience and education, while between-job dispersion is expected to increase with these two variables. This distinction, new in the literature, is formalized in the paper and empirically supported by a large sample of data for managerial compensation.

The test of learning models from the prediction above is more discriminating than others used in the literature. The prediction that compensation dispersion increases with job tenure, controlling for experience and education, is consistent with learning models. But it is also consistent with the hypothesis that there are differences in the amount of training between workers in similar job positions within a firm or among firms. When no control is made of this difference, we cannot be sure of the true explanation behind the empirical evidence. Predictions of compensation dispersion within job positions refer to the period before entering the current job and therefore are not affected by differences in training between workers of similar positions in the hierarchy.

One limitation of our data is that we can not monitor the careers of managers within their firms' hierarchy because managers can not be individually identified. Neither do we know whether a manager is externally hired or internally promoted. For this reason our analysis can not deal with the hypothesis postulated by Greenwald (1986) and Novos (1992) about differences in information about the innate abilities of managers that are internally promoted versus managers that are externally recruited, and the implications for turnover and promotion rates. We expect future research to address these questions. 


\section{REFERENCES:}

Altonji, J.G. and C.R. Pierret, 2001, Employer learning and statistical discrimination, The Quarterly Journal of Economics, 116, 313- 350.

Andersson, F. 2002, Career concerns, contracts, and effort distortions, Journal of Labor Economics, 20, 42- 58.

Auriol, E. and F. Guido and L. Pechlivanos, 2002, Career concerns in teams, Journal of Labor Economics, 20, 289- 307.

Baker, G. and M. Gibbs and B. Holmstrom, 1994, The wage policy of a firm, The Quarterly Journal of Economics, 109, 921-955.

Bauer, T.K. and J.P. Haisken-DeNew, 2001. Employer learning and the returns to schooling, Labour Economics, 8, 161-180.

Becker, G.S., 1964, Human Capital, New York: Columbia University Press.

Bernhardt, D., 1995, Strategic promotion and compensation, Review of Economic Studies, 62,315-339.

Blaug M., 1976, The empirical status of human capital theory: a slightly jaundiced survey, Journal of Economic Literature, 14, 827-55. Limited.

Blaug M. 1992. The Economic value of education, Edward Elgar Publishing

Chevalier, J. and G. Ellison, 1999, Career concerns of mutual fund managers, The Quarterly Journal of Economics, 114, 389-432.

Conyon, M.J. and I.P. Simon, and V.S. Graham, 2001, Corporate tournaments and executive compensation: evidence from the U.K., Strategic Management Journal, 22, 805-815.

Cappelli, P. and W.F. Cascio, 1991, Why some jobs command wage premiums: A test of career tournament and internal labor market hypotheses, Academy of Management Journal, 34, 848-868. Inc.

DeGroot , M.H., 1970, Optimal Statistical Decisions, New York: McGraw-Hill

Eriksson, T., 1999, Executive Compensation and Tournament Theory: Empirical Test on Danish Data, Journal of Labor Economics, 17, 262-280.

Farber, H.S. and R. Gibbons, 1996, Learning and Wage Dynamics, The Quarterly Journal of Economics, 111, 1007- 1047.

Foster, A.D. and M.R. Rosenzweig, 1993, Information Learning, and Wage Rates in Low-Income Rural Areas, The Journal of Human Resources, 28, 759-790.

Garicano, L., 2000, Hierarchies and the Organization of Knowledge in Production, Journal of Political Economy, 108, 874-904. 
Gerhart, B. and G. Milkovich, 1990, Organizational differences in managerial compensation and financial performance, Academy of Management Journal, 33, 663691.

Gibbons, R. and K. Murphy, 1992, Optimal incentives contracts in the presence of career concerns: theory and evidence, Journal of Political Economy, 100, 468-505.

Gibbons, R. and M. Waldman, 1999 (a), A Theory of Wage and Promotion Dynamics inside Firms, The Quarterly Journal of Economics, 114, 1321-1358.

Gibbons, R. and M. Waldman, 1999 (b), Careers in Organizations: Theory and Evidence. Handbook of Labor Economics, vol. 3, chapter 36, p. 2373-2437. Edited by O. Ashenfelter and D. Card, Elseiver Science B.V.

Greene, W.H., 1998, Econometric Analysis, London: Prentice-Hall International Limited, $3^{\text {rd }}$ Edition.

Greenwald, B.C., 1986, Adverse selection in the labour market, Review of Economic Studies, 53, 325-347.

Harris, M. and B. Holmstrom, 1982, A theory of wage dynamics, Review of Economic Studies, 49, 315-333.

Harvey, A., 1976, Estimating regression models with multiplicative heteroskedasticity, Econometrica, 44, 461-465.

Holmstrom, B., 1982, Managerial Incentive Schemes -a Dynamic Perspective, Essays in Economics and Management in Honour of Lars Wahlbeck, Helsinki: Swenska Handelshögkolan. Reedited in Review of Economic Studies, 66 (1999) 169-182.

Hong, H. and J.D. Kubik, 2003, Analysing the analysts: Career concerns and biased earnings forecasts, Journal of Finance, 58, 313-351.

Lazear, E. and S. Rosen, 1981, Rank order tournaments as optimum labour contracts, Journal of Political Economy, 89, 841-864.

Leonard, J., 1990, Executive pay and firm performance, Industrial and Labour Relations Review, 43, 13-29.

Mincer, J., 1974, Schooling, experience, and earnings, New York: Columbia University Press for N.B.E.R.

Murphy, K.J., 1986, Incentives, learning, and compensation: a theoretical and empirical investigation of managerial labor contracts, Rand Journal of Economics, 17, 59-76.

Novos, I.E., 1992, Learning by doing, adverse selection, and firm structure, Journal of Economic Behavior and Organization, 19, 17-39.

Ortín-Angel, P. and V. Salas-Fumás, 1998, Agency theory and internal labor markers explanations of bonus payments. Empirical evidence from Spanish firms, Journal of Economics and Management Strategy, 7, 573- 613.

Ortín-Angel, P. and Salas-Fumás, V., 2002, Compensation and span of control in hierarchical organizations, Journal of Labor Economics, 20, 848- 876. 
Poppo, L. and K. Weigelt, 2000, A test of the Resource-Based Model Using Baseball Free agents, Journal of Economics and Management Strategy, 9, 585- 614.

Rosen, S., 1986, Prizes and incentives in elimination tournaments, American Economic Review, 76, 701-715.

Salop, J and S. Salop, 1976, Self-Selection and Turnover in the Labor Market, The Quarterly Journal of Economics, 90, 619-628.

Sattinger, M., 1975, Comparative advantage and the distribution of earnings, Journal of Economic Literature, 43, 455-468.

Spence, M., 1976, Competition in salaries, credentials, and signalling prerequisites for jobs, The Quarterly Journal of Economics, 90, 51-74.

Topel, R., 1991, Specific capital, mobility, and wages: Wages rise with the job seniority, Journal of Political Economy, 99, 146-176.

Waldman, M., 1984, Job assignments, signaling and efficiency, Rand Journal of Economics, 25, 255-267.

Waldman, M., 1990, Up- or- out contracts: a signaling perspective, Journal of Labor Economics, 8, 230-250. 
TABLE 1. MEAN AND STANDARD DEVIATION FOR SALARY AND EXPLANATORY VARIABLES OF THE MODEL.

\begin{tabular}{|l|r|c|}
\hline \multicolumn{1}{|c|}{ VARIABLES } & MEAN & STANDARD DEVIATION (S.D.) \\
\hline SALARY $(w)$ & $6,341.2020$ & $3,198.9080$ \\
SUP & 0.4081 & 0.4915 \\
MED & 0.3669 & 0.4820 \\
OTHER & 0.2250 & 0.4176 \\
$A G E(A)$ & 42.8292 & 8.7184 \\
$J O B$ TENURE $(J)$ & 7.1170 & 6.6284 \\
$H_{1}$ & 0.0690 & 0.2535 \\
$H_{2}$ & 0.0191 & 0.1368 \\
$H_{3}$ & 0.2932 & 0.4552 \\
$H_{4}$ & 0.4277 & 0.4947 \\
$H_{5}$ & 0.1509 & 0.3580 \\
$H_{6}$ & 0.0401 & 0.1963 \\
$P R O D$ & 0.3434 & 0.4749 \\
$M A R K$ & 0.2644 & 0.4410 \\
$A D M$ & 0.3041 & 0.4600 \\
\hline
\end{tabular}

Variables related to compensation are expressed in thousands of 1990 pesetas. Average exchange rate during that year was 120 pesetas per US dollar. 
TABLE 2. DESCRIPTIVE INFORMATION, MEAN AND STANDARD DEVIATION FOR SALARIES AND LOG SALARIES AS A FUNCTION OF EDUCATION, AGE, HIERARCHICAL POSITIONS AND FUNCTIONAL AREA OF MANAGERS IN THE SAMPLE.

\begin{tabular}{|l|c|c|c|c|}
\cline { 2 - 5 } \multicolumn{1}{c|}{} & \multicolumn{2}{c|}{ SALARY $(\boldsymbol{w})$} & \multicolumn{2}{c|}{ LOG SALARY (Ln $\boldsymbol{w})$} \\
\hline VARIABLES & MEAN & S.D. & MEAN & S.D. \\
\hline MEP & 7,644 & 3,692 & 8.8469 & 0.4251 \\
OTHER & 5,778 & 2,431 & 8.5908 & 0.3648 \\
\hline$A G E$ (Quartile 4) & 4,897 & 2,333 & 8.4154 & 0.3825 \\
$A G E($ Quartile 3) & 7,250 & 3,853 & 8.7766 & 0.4606 \\
$A G E($ Quartile 2) & 6,980 & 3,394 & 8.7555 & 0.4259 \\
$A G E($ Quartile 1) & 6,320 & 2,857 & 8.6685 & 0.3952 \\
\hline$H_{1}$ & 5,008 & 2,112 & 8.4490 & 0.3619 \\
$H_{2}$ & 13,096 & 4,743 & 9.4222 & 0.3358 \\
$H_{3}$ & 9,599 & 2,956 & 9.1224 & 0.3128 \\
$H_{4}$ & 7,215 & 2,594 & 8.8232 & 0.3498 \\
$H_{5}$ & 5,271 & 1,879 & 8.5144 & 0.3299 \\
$H_{6}$ & 4,702 & 1,502 & 8.4066 & 0.3133 \\
\hline PROD & 4,355 & 1,281 & 8.3388 & 0.2823 \\
$M A R K$ & 5,309 & 2,119 & 8.5055 & 0.3745 \\
$A D M$ & 6,302 & 2,431 & 8.6874 & 0.3410 \\
\hline
\end{tabular}


TABLE 3. HUMAN CAPITAL AND LEARNING AS DETERMINANTS OF MANAGERS' LEVEL AND VARIANCE OF COMPENSATION

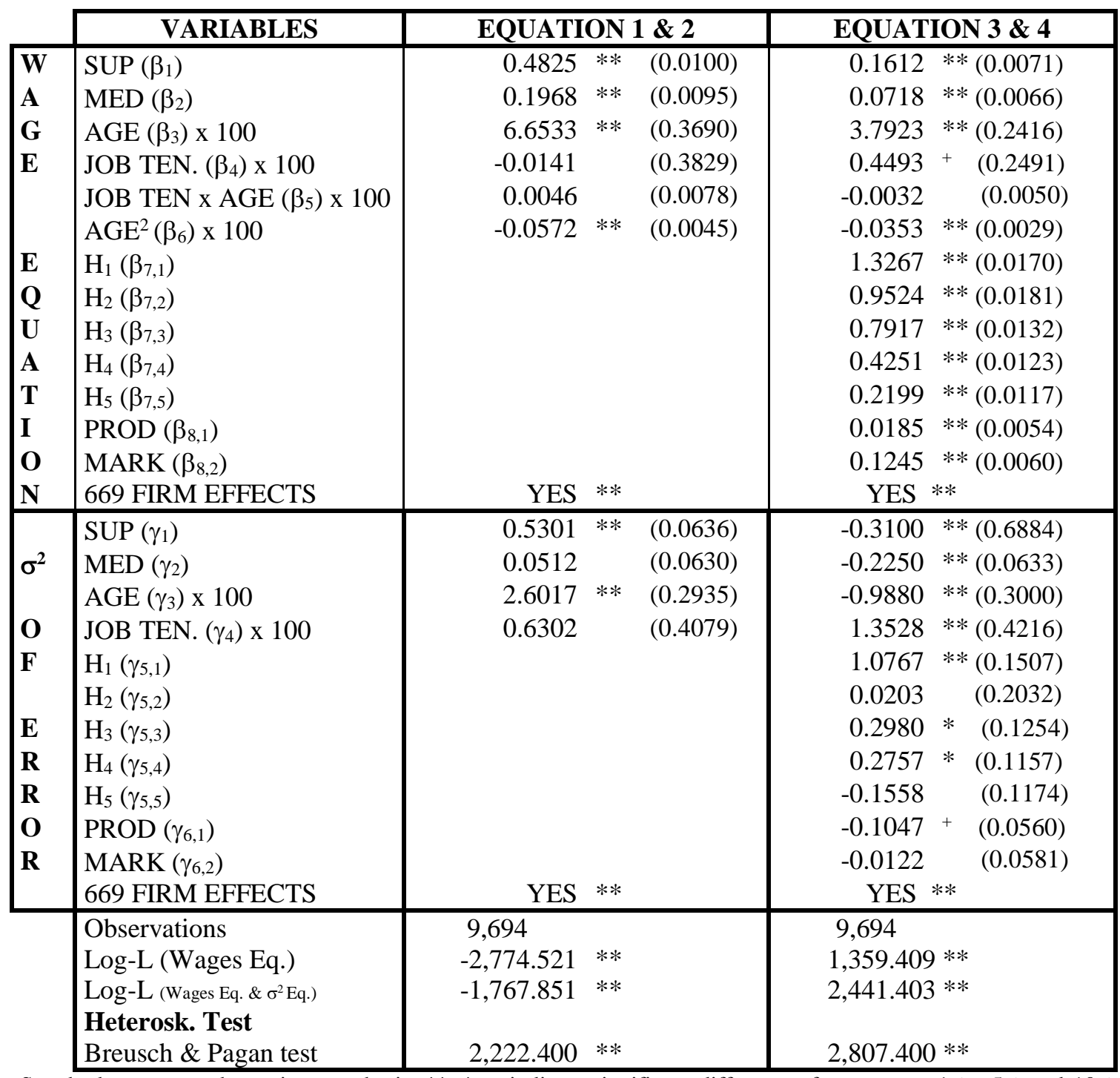

Standard errors are shown in parenthesis. $* *, *,+$ indicate significant differences from zero at $1 \%, 5 \%$ and $10 \%$ respectively. The level of significance associated with the firms' effects refers to the likelihood-ratio test where the restricted model does not include the firms' effects. In the case of the Log-L coefficients, the level of significance refers to the likelihood-ratio test where (a) the restricted model is only a constant term for the Log-L (Wage Equation), and (b) the restricted model is the wage equation for the Log-L(Wage Equation \& $\sigma^{2}$ Equation). The Breusch $\neg$ Pagan test is the usual test for the existence of heteroskedasticity when its determinants are known, see chapter 12, Greene (1998). 